\title{
A GROUNDWATER ARTIFICIAL RECHARGE MANAGEMENT TOOL: A CASE STUDY OF THE DRAVA RIVER IN MARIBOR, SLOVENIA
}

\author{
IRENA KOPAČ, MATEVŽ VREMEC \& MIHA KRAČUN \\ IEI - Institute for Ecological Engineering, Slovenia
}

\begin{abstract}
Slovenia is divided into two river basin districts: the Danube and the North Adriatic. The Vrbanski Plato aquifer, which presents both natural and artificial bank filtration from the river Drava, is a part of the Danube river basin district and is the most important water source for 14 municipalities in the northeast part of Slovenia. This public water supply system, managed by the Maribor Water Supply company, is the largest water supply system in Slovenia. This organized method of riverbank filtration in Slovenia began about 50 years ago in the Vrbanski Plato aquifer. The bank filtrated waters of the Drava River are used, which crosses an old geological riverbed of the city of Maribor. As the next step, four wells were constructed (in 1978) on the island in the river and this water was then filtrated via negative wells at a $250 \mathrm{~m}$ distance from drinking water wells. This was the first step for managing the groundwater recharge, but a widening has been planned to protect this water resource from the possible influence of pollutants from the city's side. In this area, we have had a well-organized groundwater monitoring for years. From this point of view, the Vrbanski Plato was very suitable for the case study in the FREEWAT project (FREE and open source software tools for WATer resource management), which is an EU HORIZON 2020 project. The FREEWAT platform is, at present, a large QGIS plugin, allowing a coupling of the power of the GIS geo-processing and post-processing tools in spatial data analysis with that of process-based simulation models. We used the QGIS/FREEWAT tool for building a groundwater model and to present the efficiency of the existing artificial groundwater recharge and to look at the plans. During the first half of the project and the preparation of the groundwater model, there was an incident with the spillage of heating oil in the area where the groundwater flow is divided both toward the wells and in the opposite direction. The division of the water changes its position as a function of the quantities of pumped water and the height of the impounded river, Drava. Within the activities of the FREEWAT project, we have tried to integrate in the process of groundwater modelling stakeholders for a broader understanding and effective water management.
\end{abstract}

Keywords: FREEWAT, open source and public domain software, HORIZON 2020, water resource management, Vrbanski Plato aquifer, induced riverbank filtration, artificial groundwater recharge.

\section{INTRODUCTION}

The organized riverbank filtration was first applied in Slovenia in the Maribor water supply system on the Vrbanski Plato aquifer about 50 years ago. The Maribor water supply system provides water to the region (about $600 \mathrm{~km}^{2}$ and with about 200,000 residents). With 1300 $\mathrm{km}$ of water supply pipes, 37 wells, and 73 water reservoirs, this is the largest system of water in Slovenia. The Vrbanski Plato aquifer represents the most important water resource in this system and with a total capacity of $760 \mathrm{~L} / \mathrm{s}$, the pumping station of Vrbanski Plato is able to meet the whole water needs of this region, but for now, it covers up to $70 \%$, depending on the functioning other pumping stations and other water resources. Some of them are more climate dependant as is the Vrbanski Plato and in drought periods, we need more water from the Vrbanski Plato. In 2015, for example, the Vrbanski Plato pumping station comprised $60 \%$ of the Maribor drinking water supply. 


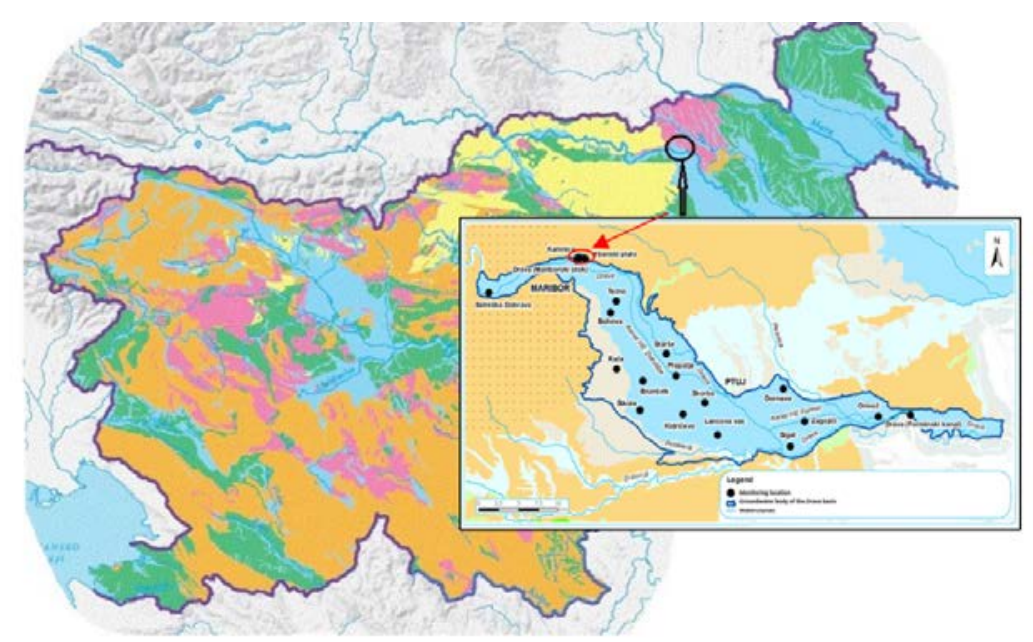

Figure 1: Location of the Vrbanski Plato aquifer.

The use of bank filtrated waters of the Drava River did not begin in an intensive way. The wells were drilled into the aquifer of a geologically abandoned riverbed at a distance of about $800 \mathrm{~m}$ upstream and $1200 \mathrm{~m}$ downstream of the banks of the river. By pumping the wells, the bank infiltration was induced from both the upstream and downstream banks of the river. More intensive bank filtration began twenty years ago on the island situated in the middle of the Drava River. This filtrate is now applied as an artificial recharge of the aquifer mentioned to augment the existing $400 \mathrm{l} / \mathrm{s}$ capacity of the aquifer and, at the same time, protect the drinking groundwater against the endangering pollution from the city. Four wells on the island were constructed, each $75 \mathrm{l} / \mathrm{s}$, together having $300 \mathrm{l} / \mathrm{s}$ capacity. This bank water is then infiltrated via negative wells at a $250 \mathrm{~m}$ distance from the drinking water wells. The negative wells could have been first constructed on the other site of the pumping wells, opposite to the city. But at that time, it was, due to insurmountable reasons, not possible. Now the whole system has been foreseen, including the missing negative wells opposite to the city. In these 50 years of the operation, two groundwater contaminations occurred on the city side; the first was $\mathrm{Cr}+6$ and later, the Threehalomethanes. In both cases, the artificial recharge was very useful for rapidly recovering the system (Rismal and Kopač [1]).

Since the end of 1986, with the first phase of the artificial groundwater recharge fully carried out, until 1992, detailed control measurements were conducted, which ensured the integrity of Maribor Island and protected the groundwater quality. Later, the monitoring focused primarily on the quality and the level of the groundwater. On the basis of these observations, the data of several groundwater models of the Vrbanski Plato were made. These models have been following trends in their field, but they never got enough attention from stakeholders or water management. Participation in the FREEWAT project has given us a new opportunity to show the importance of groundwater modelling in Induced RiverBank Filtration (IRBF) as a widely used technique in the Managed Aquifer Recharge (MAR). The project will result in an open source and public domain for a GIS integrated modelling environment model for simulating water quantity and quality in both surface and groundwater with an integrated water management and planning module (Rossetto et al. [2]). The conducted study investigated the groundwater-surface water interaction between the Drava River and the porous aquifer in the old geological riverbed of the Drava River. The 
reason for the case study derives from a desire for good understanding of aquifer: the Drava relation and the impact of artificial groundwater recharging, which is induced riverbank filtration. For further development of the exploitation of the Vrbanski Plato aquifer, it is very important to know the influences of:

- $\quad$ water management (drinking water supply, industrial);

- the first step of artificial groundwater recharge and a planned second step;

- the groundwater pollution problem (particularly from the Maribor city centre) and solute transport.

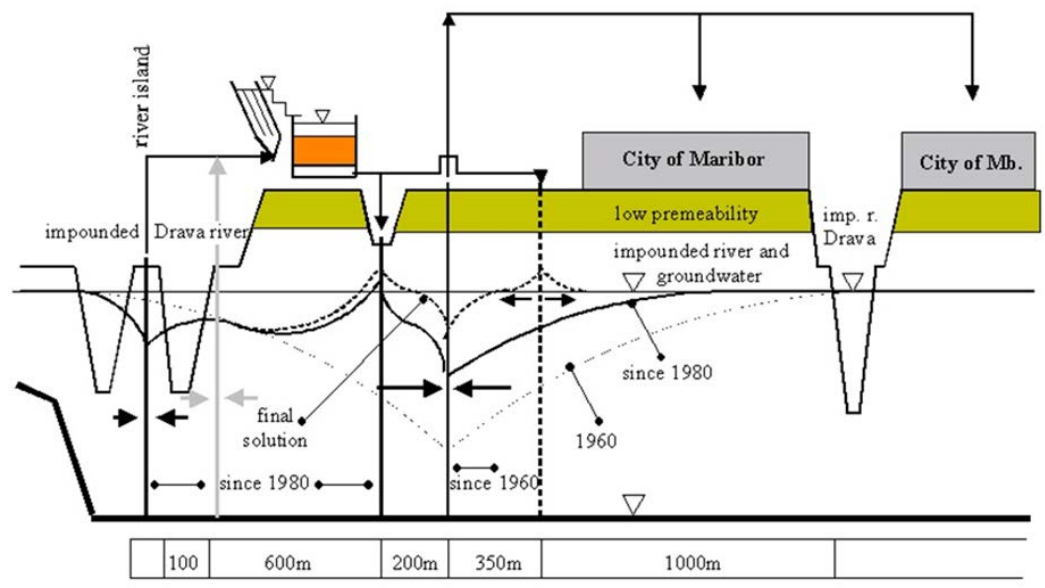

Figure 2: General scheme of the existing and planned IRBF system - cross section (Rismal and Kopač [1]).

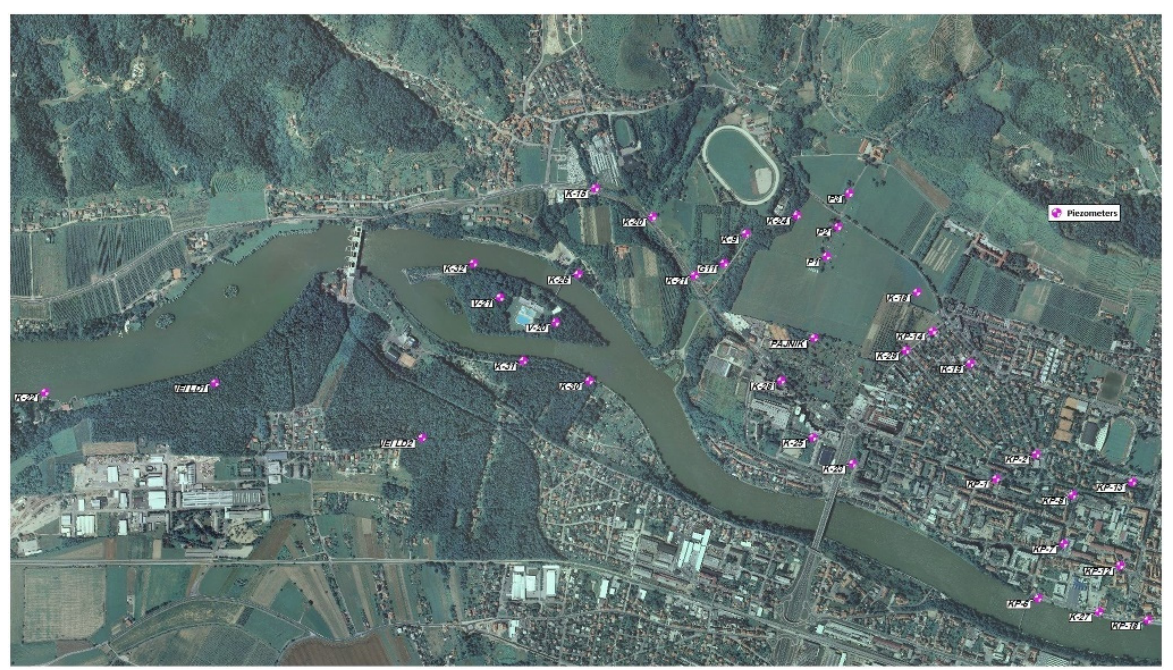

Figure 3: Groundwater monitoring in the Vrbanski Plato. 


\section{DESCRIPTION OF THE GROUNDWATER AQUIFER}

The first major pumping station on the aquifer of the Vrbanski Plato was built between 1956 and 1959, when the municipality had to build an experimental pumping station due to a lack of a drinking water supply. Before the construction of the dam in Melje and the hydroelectric power plant in Zlatoličje, the predicted usage capacity of drinking water was estimated to be around $100 \mathrm{~L} / \mathrm{s}$. Due to the construction of the dam in Melje the level of the Drava River rose and increased the yield of the aquifer to where it is now possible to pump up to $460 \mathrm{~L} / \mathrm{s}$ without specific measures and $760 \mathrm{~L} / \mathrm{s}$ with the first step of MAR.

Fig. 4 shows the groundwater flow in the area of the Vrbanski Plato. In the western part of the Limbuška Dobrava, the Drava infiltrates into the aquifer's groundwater body above the HEPP Maribor Island, which is then merged with the hinterland waters flowing from the Pohorje hill. The groundwater direction is then in the direction of Maribor Island in the middle of the Drava River, where the river additionally infiltrates the groundwater. In the area of the Maribor Island, there are also pumping wells for the first step of the artificial groundwater recharge system. The groundwater then flows to the pumping station of the Vrbanski Plato. From the other side of the city, the groundwater flow is a consequence of the groundwater depression, which is created by the drawdown in the pumping station. The flow from the direction of the city centre is recharged by the Drava, which infiltrates the Lent area (part of the city).

In the city centre, a groundwater divide occurs, as a part of the groundwater flows to the pumping station and the other detours towards the industrial part of the city known as Melje. When the dam was built, the level of the Drava was a little higher as is the height of the terrain. For this reason, an impermeable barrier was constructed with drainage for draining the groundwater below the Melje dam into the Drava River. Between Maribor Island and the pumping station, the Vrbanski Plato in the Vinarje Valley is the location of infiltration wells for artificial recharge of groundwater.

\section{GROUNDWATER MODELLING - USE OF THE QGIS/FREEWAT TOOL}

In this area, we have a very good and advanced monitoring network. So far, we have been lacking the adequate modelling tool that should be accessible to the professionals and to the operator of the water supply system and responsible for water management at the governmental and local level. The QGIS/FREEWAT tool pointed out an interesting

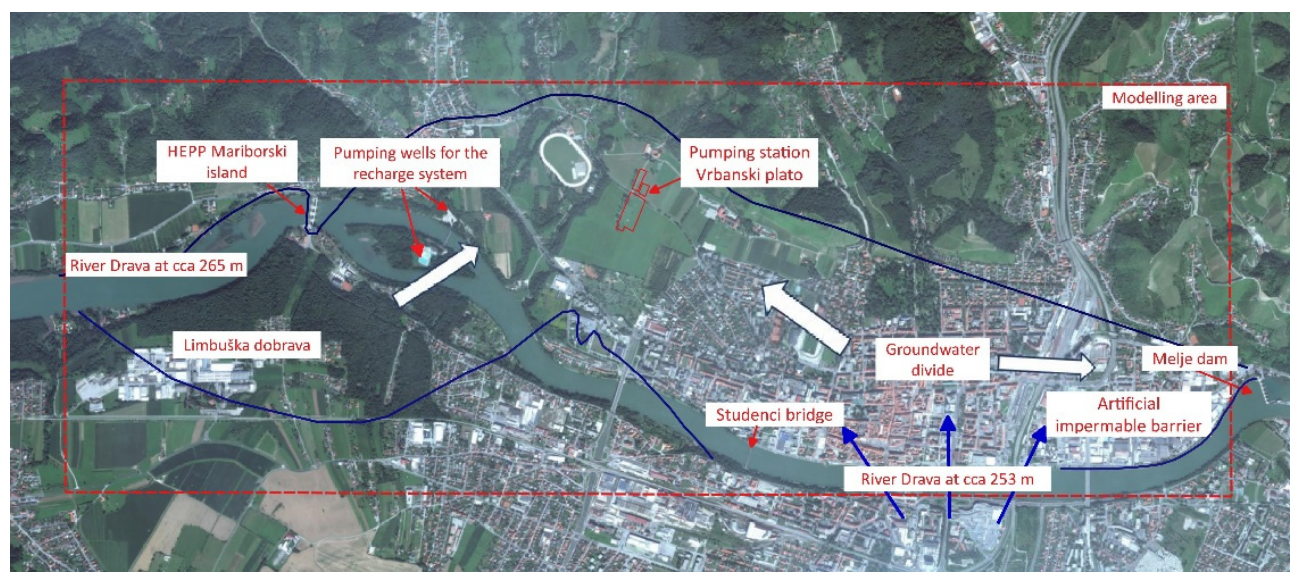

Figure 4: Conceptual model. 
challenge: how can we integrate the GIS spatial data with the modelling and interpretation of results and get an effective decision support system. The FREEWAT plugin operates within the open source geographic information system QGIS with a GNU license (General Public License). The program operates within all operating systems and supports both raster and vector data, databases, and offers a wide range of other functional tools and is compatible with all commercial GIS software (ArcInfo, Mapinfo, Autocad Map). In Fig. 5, we show how the different modules in this tool are interconnected as well as their capabilities.

We divided the work into the following steps:

1. first, we collected all relevant GIS data (raster and vector) - land use, digital elevation model, topography base map, surface geology, surface water network, elevation of the Drava riverbed and the width of the river;

2. we collected data from groundwater and surface water monitoring (head and quality), pumping rates, precipitation and evapotranspiration;

3. we prepared the impermeable base of the aquifer; we have some new data from piezometers and a new interpolation was needed;

4. the construction of a steady-state model with a $50 \times 50 \mathrm{~m}$ grid cell size and an upgrade to the transient model, calibration and validation, a simulation of different scenarios focused on changing the location of the groundwater flow divide line below the city;

5. the construction of the transient model with a $5 \times 5 \mathrm{~m}$ grid cell size for monitoring the impact of the spill of heating oil and rehabilitation with two newly constructed pumping wells.

Based on factors that influence the Vrbanski Plato pumping station and the pre-existing models, the active model area was limited to the area from Limbuška Dobrava to the dam in

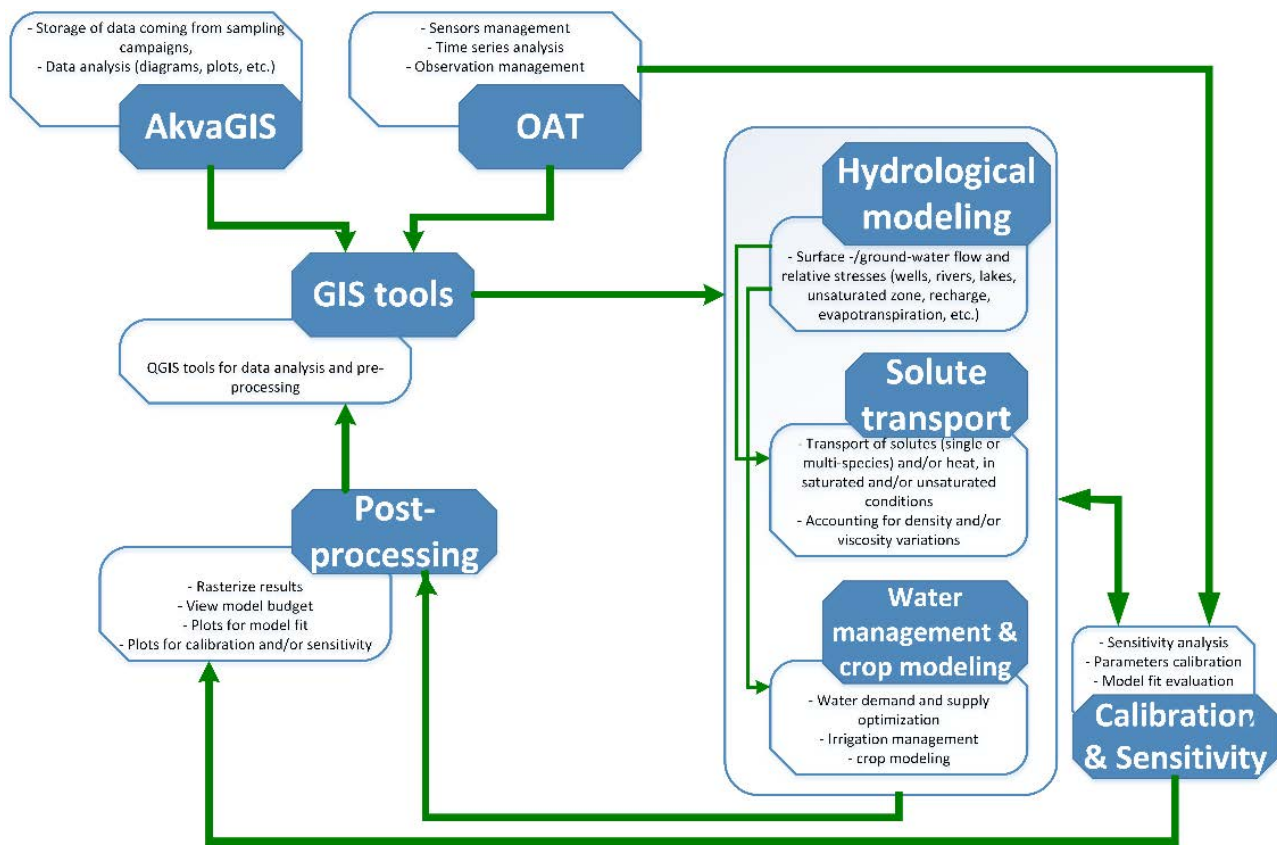

Figure 5: QGIS/FREEWAT Tool - interconnected different modules (FREEWAT [3]). 

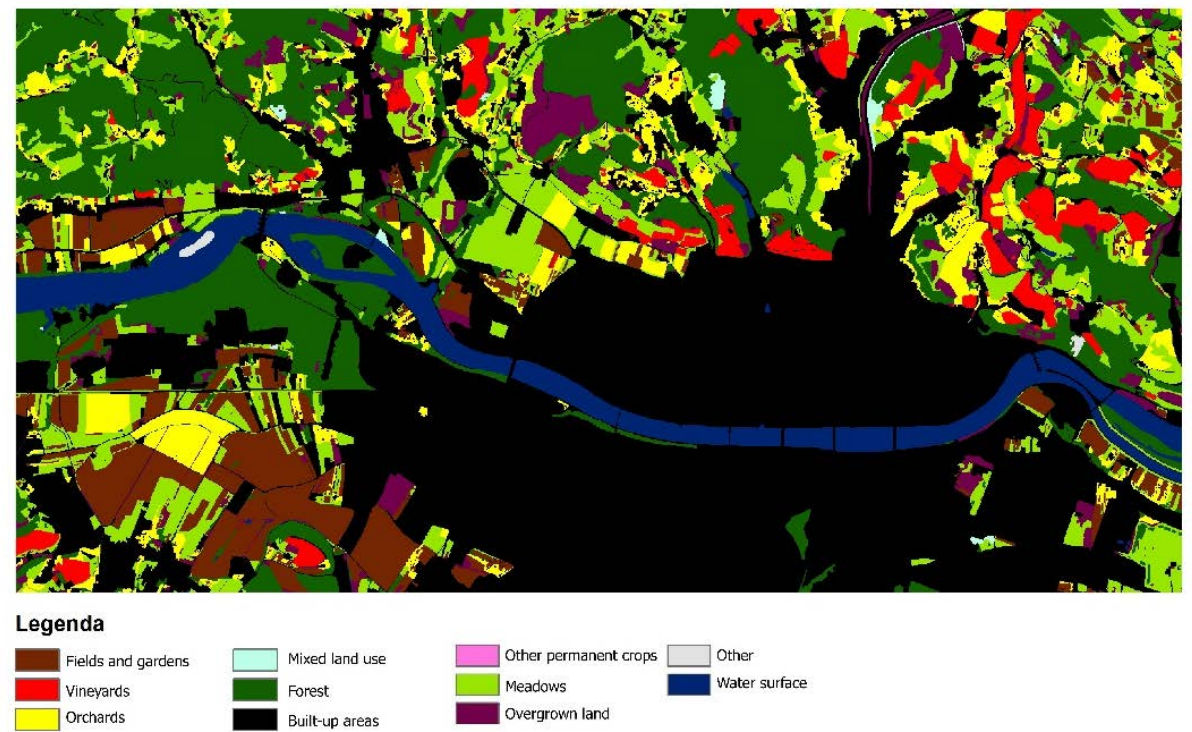

Figure 6: Land use in model domain.

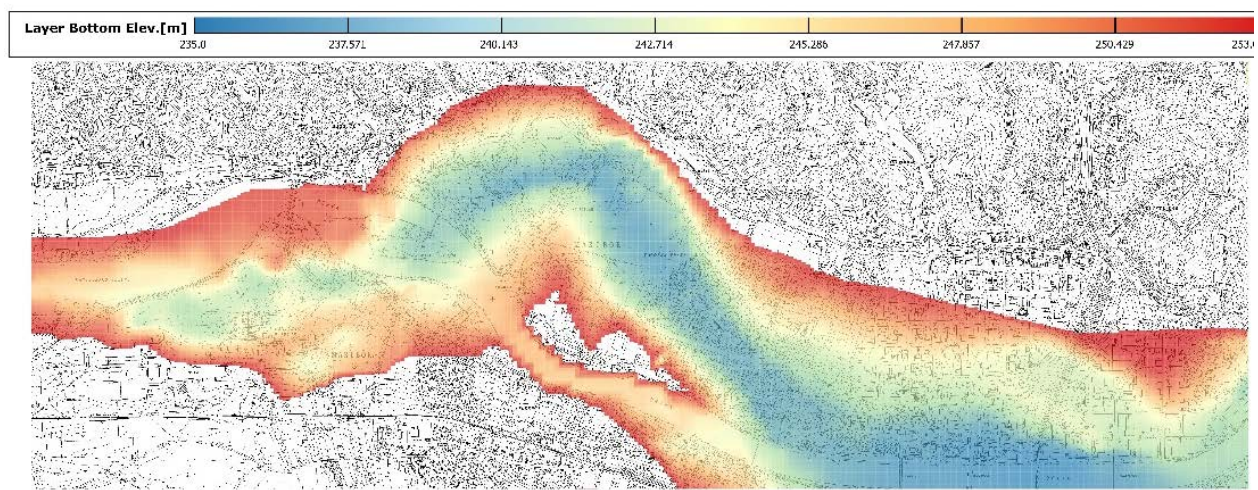

Figure 7: Impermeable base of the Vrbanski Plato aquifer.

Melje. For the purpose of the $50 \times 50 \mathrm{~m}$ grid size model, we created a model grid consisting of 45 rows and 128 columns, which produced a grid with 5760 cells. For the purpose of the $5 \times 5 \mathrm{~m}$ grid size model, we created a model grid consisting of 450 rows and 1280 columns, which produced a grid with 576000 cells.

Fig. 8 displays the division of the grid on active cells (colourless) and inactive cells (teal section). In the model, the inactive cells represent the areas that do not directly affect the groundwater flow and in which there is no flow between cells. The topmost surface of the model was defined using a digital elevation model and the bottom surface with an interpolated impermeable bedrock height obtained from bores and piezometers across the area. The model is defined with one unconfined layer. 


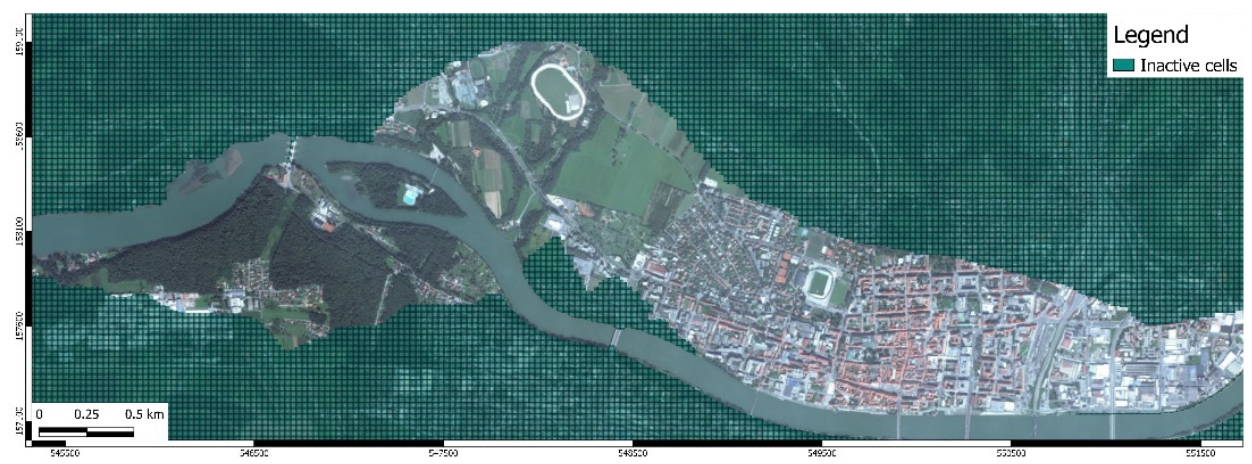

Figure 8: Model domain of the Vrbanski Plato aquifer - active and inactive cells.

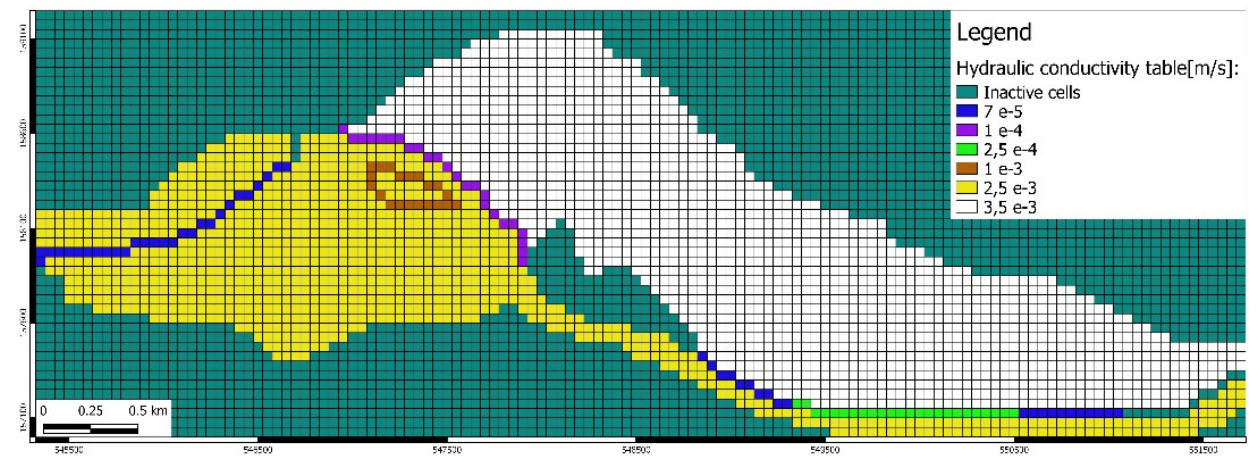

Figure 9: Hydraulic conductivity of the Vrbanski Plato aquifer.

The geometrical and hydrogeological characteristics of the aquifer were determined based on pre-made reports and research in this area. The research carried out estimated the hydraulic conductivity of the aquifer to range from $1.10-3 \mathrm{~m} / \mathrm{s}$ to $8.10-3 \mathrm{~m} / \mathrm{s}$ and also indicated lower hydraulic conductivity values in the area of the riverbed due to soil settling, which is currently sealing areas of the riverbed contributing to a lower hydraulic conductivity than in the rest of the aquifer (Kopač [4]).The input data of the hydraulic conductivity values used for the model area were first estimated based on existing research and then calibrated based on the ground water level at piezometers represented in the figure.

The groundwater hydrology of our model area is extremely diverse, which allowed us to test different packages for boundary conditions. For the model area, the next boundary conditions were taken into account:

- the RIVER package - infiltration of the Drava: the geometry of the river bottom was determined based on measurements of the cross sections of the river,

- the RECHARGE package - surface precipitation of two zones (city area and green area),

- the CHD package - hinterland groundwater flow from the Pohorje mountains,

- the WELL package: pumping from 4 pumping wells on Maribor Island and 14 pumping wells in the area of the Vrbanski Plato pumping station, 2 pumping wells 
in area of heating oil pollution, and 2 artificial groundwater recharge wells in the area of the Vinarje brook,

- the DRN - the draining of groundwater in Melje.

For the calibration of the model, we used the groundwater level data (2015) from six piezometers located throughout the model area (Fig. 11). More groundwater data from five piezometers was also used for validating the calibrated model (Fig. 11). The maximum deviation, which is taken into account in the calibration between the piezometer's actual groundwater level and the simulated groundwater level, was $15 \mathrm{~cm}$. The model was validated after the calibration was carried out with an assessment of the reliability of the other 5 piezometers, which were not used in the calibration.

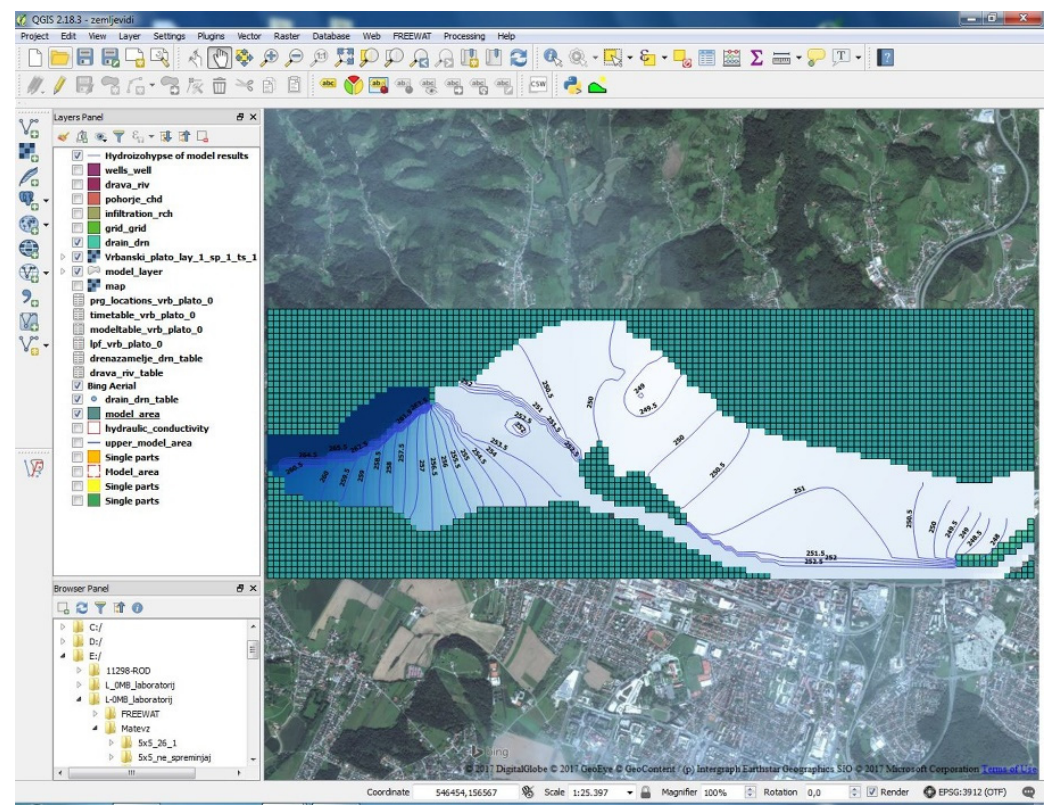

Figure 10: Groundwater model of the Vrbanski Plato aquifer.

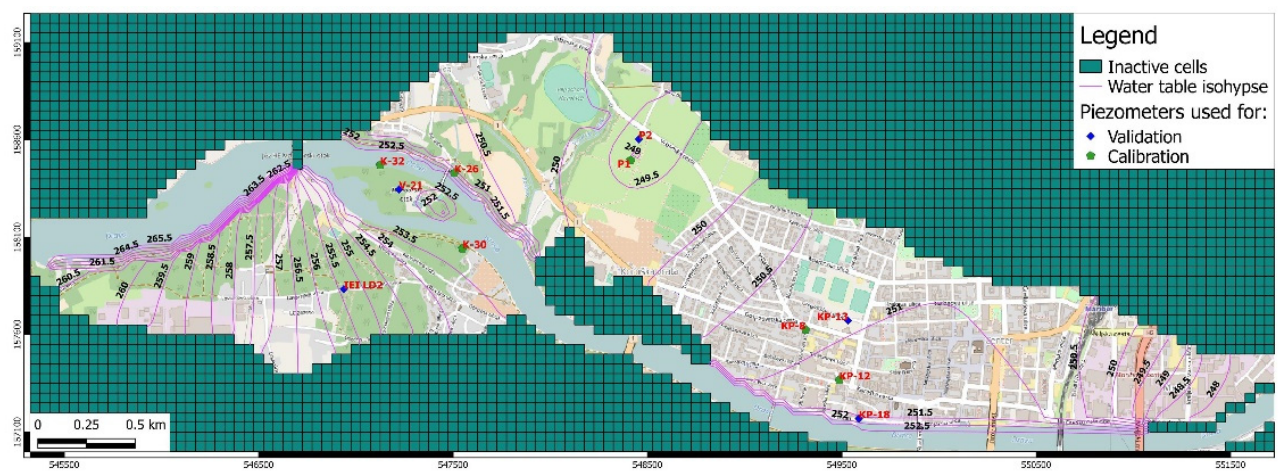

Figure 11: Model calibration and validation. 


\section{HEATING OIL SPILLAGE AND REMEDIATION}

In March 2016, a large quantity of heating oil was spilled in the inner city of Maribor. A leak was detected in a supply pipe between a heating oil tank and the boiler room of the municipality building. Due the fact that the spill site was in a water protected area, immediate intervention and remediation measures had to be carried out. The first steps included the historical research of the spillage, an on-site inspection with water sampling at the nearest existing observations wells, a soil laboratory analysis of new boreholes and the excavation of the upper layer of contaminated soil. The excavation was limited by the stability of the municipality building and the $25 \mathrm{~m}$ thick unsaturated zone. By analysing the sequence of events, we found that, over a short period of time, approximately $20 \mathrm{~m}^{3}$ of heating oil was spilled partly reaching the aquifer and forming a floating oil lens.

Groundwater sampling at the nearest existing boreholes showed that the contaminant did not spread to a larger area. For the localization of the oil plume and recovery measures, three new boreholes were drilled. One was located directly on the site of the spillage, the second and third in the most probable directions of the spreading. The groundwater level, quality monitoring and the installation of a small pump mounted in a borehole (P-MOM-01) at the location of the spill were conducted immediately after the drilling. The small pump had two tasks: to create a cone of depression to restrain the spreading of the contaminant and to remove the oil from the floating layer in the cone of depression by lifting of the pump once a week.

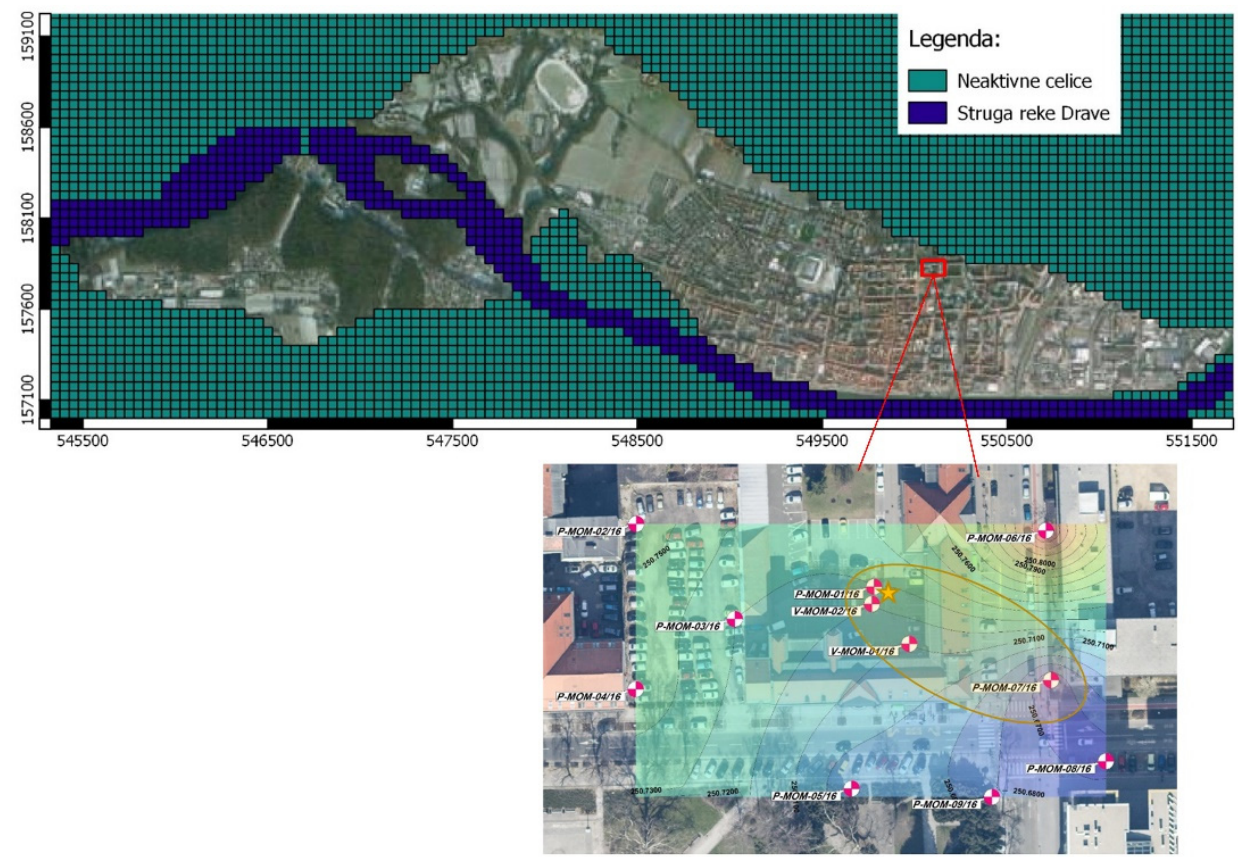

Figure 12: Estimated groundwater table in the area of the municipal building for the $19^{\text {th }}$ of October 2016. Observation wells (piezometers) were given the prefix "P" and the remediation wells were given the prefix "V". The yellow star indicates that the spill site and the yellow ellipse shows the approximate extension of the floating oil layer. 
In the second phase, an analysis of the existing hydrogeological data was carried out from the Vrbanski Plato aquifer and on the groundwater model to estimate the direction of the contaminant plume's spreading. Based on an existing groundwater model, we could estimate and determine the locations of new observation wells. It was also very important that we were able to present the local authorities with a model to illustrate how important water management is to ensure that the polluted area will not spread to the catchment area of the Vrbanski Plato pumping station.

The model simulation with an average pumping station and with active water recharge systems indicated that the spill extends towards the drain in Melje and was not threatening the quality of the drinking water pumped at Vrbanski Plato. All of the other scenarios (maximum pumping at the Vrbanski Plato or no artificial groundwater recharge) simulated the shift of the watershed divide towards Melje, consequently redirecting the oil spillage and more polluted water towards the pumping station of Vrbanski Plato instead of directing the contaminated water towards the drainage in Melje.

Based on an extended analysis and good experience with the borehole pump, a supplementary measure with the implementation of two remediation wells for a floating oil layer recovery system by dual pump-and-skim technology (Delin and Herkelrath [5]) was applied for the prevention of the spreading and long-term attenuation of the contamination. The dual pump-and-skim technology was composed of two pumps inside each remediation well with a large groundwater pump for the formation of a cone of depression and a small skimmer pump for the temporary pumping of the floating oil layer. The water was pumped into an oil separator and a storage tank that is regularly cleansed (Blažeka et al. [6]).

One year after the spill and approximately one half of the spilled oil has been recovered. With the excavation of the upper layer, $4.5-6 \mathrm{~m}^{3}$ was removed with the pumping procedure at approximately $2-3 \mathrm{~m}^{3}$ and a volume of $2-3 \mathrm{~m}^{3}$ are difficult to remove due to the sorption and entrapment of the oil in the unsaturated zone. With the setup of the recovery system in the remediation wells, the contaminant was stabilized in a depression created in the watertable. The full remediation and attenuation of the spillage will be a slow process, which will take years to recover from.

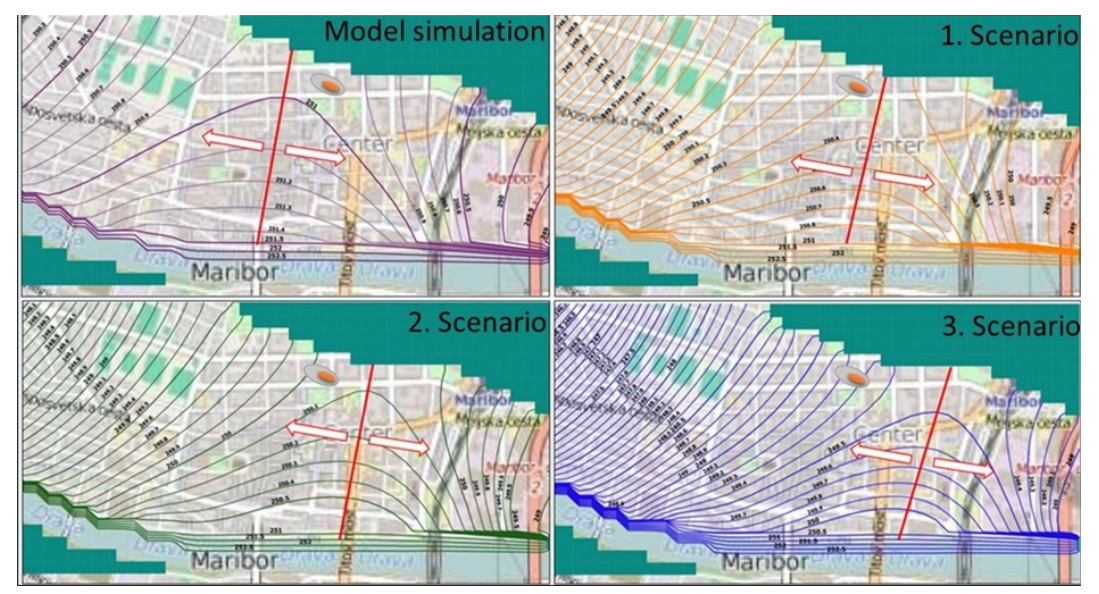

Figure 13: The location of the divide in different scenarios of water management in the catchment area of the Vrbanski Plato pumping station and the direction of the spillage is showed in the figure as: 


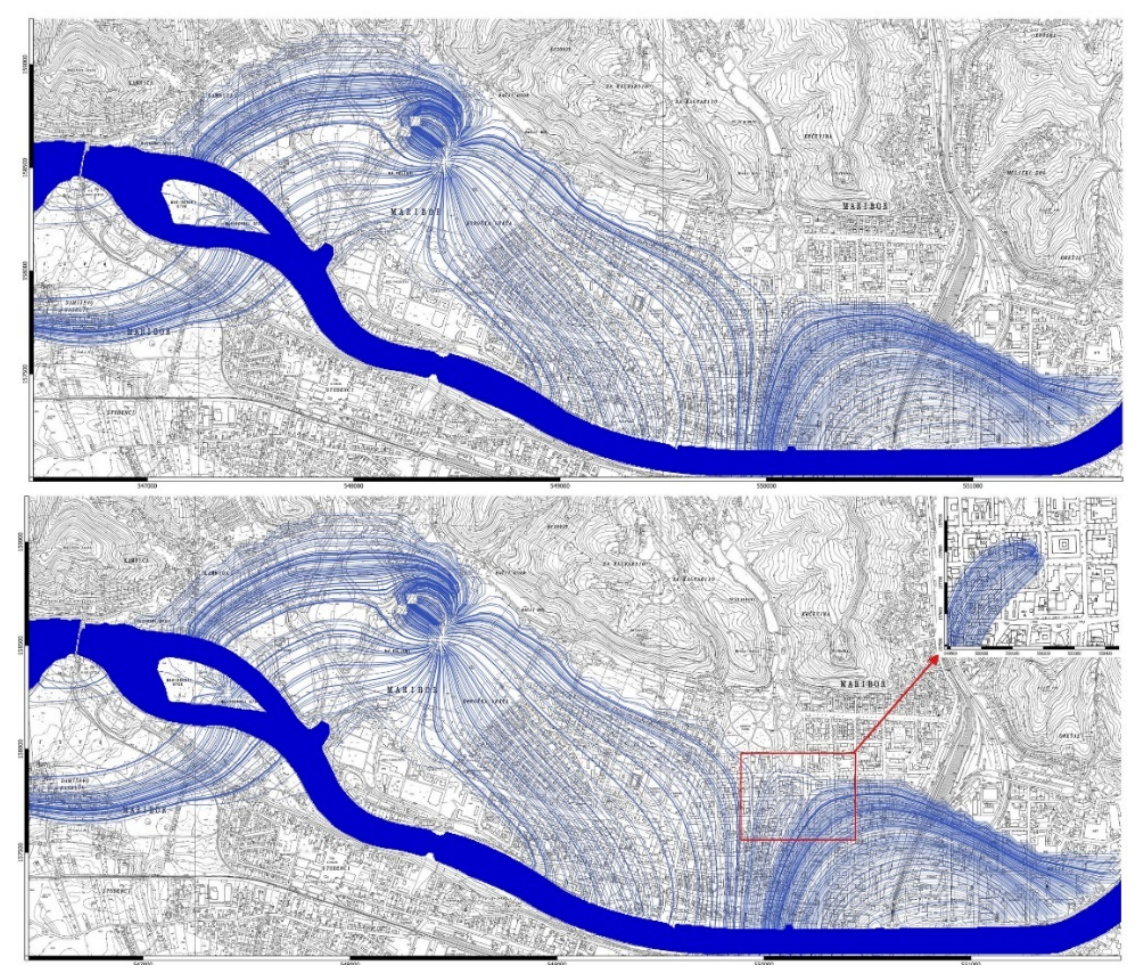

Figure 14: Particle tracking with groundwater flow to the wells in the transient model with (the top picture) and without (the bottom picture) pumping the pollution site.

With the transient model, we are now monitoring the situation. On the 19.10.2016, two pumping wells started to operate in the area of the municipality, reducing the contamination from the oil spillage that happened in this area. The simulations performed with the transient model are meant to indicate the effects of the newly constructed wells on the aquifer water table and the location of the watershed divide. The transient model includes the period from $1^{\text {st }}$ July 2014 to $30^{\text {th }}$ June 2017 . We divided the stress periods into the period before the pollution occurred, the period before the two remediation wells started to work and the period when they started to work taking into account the change in pumping.

\section{CONCLUSIONS}

The Vrbanski Plato aquifer provided us with very good conditions for induced riverbank filtration (IRBF) as part of our managed aquifer recharge schemes (MAR). Current development is lagging behind in terms of both plans and requirements. This is also connected to a poor understanding of local authorities and policy makers. The value of using advanced technologies (often referred to as "complex" in WFD related documents) in water management is often diminished by the fact that only well-trained practitioners and professionals are involved in the study and present the results to the stakeholders. Through creating a common environment among water research/professionals, policy makers and implementers, FREEWAT's main impact will be most felt in enhancing science and in the participatory approach and evidence-based decision making in water resource management, 
hence, producing relevant and appropriate outcomes for policy implementation (Rossetto et al. [7]). Our experience during the Vrbanski Plato case study was very positive. The connection data of the GIS tool, open license, and the database for monitoring and model approaches functioned as the right tool for a professional approach, communicating and exchanging ideas with stakeholders as well as for the presentation of results allowing for good visualization tools.

\section{ACKNOWLEDGEMENT}

This paper is presented within the framework of the FREEWAT project, which has received funding from the European Union's Horizon 2020 research and innovation programme under Grant Agreement n. 642224.

\section{REFERENCES}

[1] Rismal, M. \& Kopač, I., Riverbank filtration as pre-treatment of river water for artificial recharge of groundwater for drinking water supply of the city Maribor. Workshop: Attenuation of Groundwater Pollution by Bank Filtration, $15^{\text {th }}-17$ th June, Dresden, Germany, 2000.

[2] Rossetto, R., Borsi, I. \& Foglia, L., FREEWAT: FREE and open source software tools for WATer resource management, Rendiconti Online Società Geologica Italiana, 35, pp. 252-255, 2015.

[3] FREEWAT, Online. http://www.freewat.eu/. Accessed on: 19 Apr. 2017.

[4] Kopač, I., Hydrogeological model of Vrbanski Plato - Action programme for further step for artifical recharge on Vrbanski Plato; Proj. No. 6V-7H2.1, IEI - Institute for Ecological Engineering Ltd., Maribor, Slovenia, 2008.

[5] Delin, G. \& Herkelrath, W., Effects of a Dual-Pump Crude-Oil Recovery System, Bermidji, Minnesota, USA. Groundwater Monitoring and Remediation, 34, pp. 57-67, 2014.

[6] Blažeka, Ž. et al., The emergency intervention and rehabilitation works due to spillage of fuel oil in the building of the Municipality of Maribor. Proj. No. 6T-16138, IEI Institute for Ecological Engineering Ltd., Maribor, Slovenia, 2016.

[7] Rossetto, R., Foglia, L., Borsi, I. \& Kopač, I., FREEWAT - open source integrated modelling environment (surface- and groundwater). Proceedings of the 6th Croatian international Water Conference - Croatian water on investment wave, pp. 1327-1334; 20th-23rd May 2015. 